\title{
Intercâmbios virtuais e a internacionalização em casa: reflexões e implicações para a Linguística Aplicada
}

DOI: http://dx.doi.org/10.21165/el.v49i1.2469

\section{Ana Cristina Biondo Salomão'}

\section{Resumo}

Projetos telecolaborativos utilizando ferramentas digitais vêm ampliando, na atualidade, as possibilidades de internacionalização das universidades ao redor do mundo. Neste artigo, trazemos os resultados de uma pesquisa realizada no contexto do Programa Brazilian Virtual Exchange (BRaVE-UNESP) sobre as estratégias para uso de inglês como língua franca em atividades colaborativas de intercâmbio virtual adotadas por professores de diferentes áreas do conhecimento. Por meio de metodologia qualitativa, enfocamos as perspectivas dos professores em relação às dificuldades e estratégias usadas para lidar com a comunicação entre os alunos por meio da língua inglesa. Os resultados trazem reflexões e implicações para a Linguística Aplicada em relação à necessidade de se pensar diretrizes para um novo papel do professor de línguas como mediador de contextos de intercâmbios virtuais.

Palavras-chave: internacionalização; intercâmbio virtual; BRaVE; inglês como língua franca.

1 Universidade Estadual Paulista "Júlio de Mesquita Filho" (UNESP), Araraquara, São Paulo,

Brasil; ana.salomao@unesp.br; http://orcid.org/0000-0002-1531-8551 


\title{
Virtual exchanges and internationalization at home: reflections and implications for Applied Linguistics
}

\begin{abstract}
Nowadays, telecollaborative projects using digital tools have been expanding the possibilities for universities internationalization around the world. In this article, we show the results of a research conducted in the context of the Brazilian Virtual Exchange Program (BRaVE-UNESP) on strategies to use English as a lingua franca in collaborative virtual exchange activities adopted by teachers from different areas of knowledge. Through qualitative methodology, we focus on teachers' perspectives on the difficulties and strategies used to deal with communication among students in the English language. The results bring reflections and implications for Applied Linguistics regarding the need to think about guidelines for a new role of the language teacher as a mediator in virtual exchange contexts.
\end{abstract}

Keywords: internationalization; virtual exchange; Brazilian Virtual Exchange; English as a Lingua Franca.

\section{Introdução}

Com o advento das tecnologias digitais, uma gama de projetos telecolaborativos tem surgido ao redor do mundo, aproximando alunos na busca de fomentar o compartilhamento de ideias e o desenvolvimento da interculturalidade ${ }^{2}$. O'Dowd (2007) aponta para a década de 1990, quando o acesso à internet se tornou mais difundido, como sendo o berço dos projetos de colaboração online, mas adverte que a ideia de engajar estudantes em diferentes localidades é bem mais antiga. Nos anos de 1920, o educador francês Célestín Freinet conduziu um projeto com seus alunos de produção de jornais que, posteriormente, foram trocados com alunos de outras partes da França.

O'Dowd (2018) descreve a telecolaboração existente na atualidade como o engajamento de um grupo de aprendizes em interações interculturais online e projetos em colaboração com parceiros de outros contextos culturais ou localizações geográficas como parte integrante de programas educacionais. $O$ autor explica que essa atividade tem recebido diferentes nomeações como: intercâmbio intercultural online, intercâmbio ou mobilidade virtual, COIL (Collaborative Online International Learning), educação intercultural em língua

2 A interculturalidade é compreendida, neste artigo, como componente de uma educação humanística que busca o desenvolvimento da capacidade de interagir ao longo de fronteiras culturais e de compreender diferenças em relação a valores, significados e crenças, vindo ao encontro das necessidades de comunicação a distância mediadas pelas novas tecnologias (KRAMSCH, 2017; SALOMÃO, 2011). 
estrangeira mediada pela internet, ambientes de aprendizagem globalmente em rede, e-tandem e teletandem.

Nossa discussão, nesse artigo, enfoca a modalidade de intercâmbio virtual ou Virtual Exchange adotada no Programa BRaVE (Brazilian Virtual Exchange) ${ }^{3}$ implementado na UNESP em 2018, inserido no plano acadêmico de internacionalização. De acordo com relatório da CAPES sobre internacionalização das universidades brasileiras (BRASIL, 2017, p. 6), ela deve ser "encorajada de uma maneira ampla, não apenas através da mobilidade de discentes e docentes, mas também na troca de ideias, na integração da dimensão internacional ao ensino, pesquisa e extensão, funções das instituições de ensino superior".

Neste artigo, discutiremos os resultados de uma pesquisa realizada no contexto do BRaVE - UNESP sobre as dificuldades e estratégias para uso de inglês como língua franca em atividades colaborativas de intercâmbio virtual adotadas por professores de diferentes áreas do conhecimento. Entendemos que nesses contextos reside um novo papel para o professor de inglês como mediador, que poderá oferecer auxílio em relação ao planejamento das ações em conjunto entre o professor brasileiro e o estrangeiro de modo a explorar as potencialidades linguísticas de cada contexto.

Iniciaremos descrevendo o Programa BRaVE e seu desenvolvimento na UNESP por meio de exemplos de atividades inseridas em diferentes disciplinas. Posteriormente, apresentamos a metodologia de pesquisa empregada, assim como os instrumentos de coleta de dados e a forma de análise escolhida. Discutiremos então os achados por meio das categorias levantadas na análise dos dados sobre as dificuldades e estratégias usadas pelos professores para lidar com a comunicação entre os alunos por meio do inglês. Encerraremos com nossas reflexões sobre as implicações dos resultados para a Linguística Aplicada no que tange ao ensino de línguas e à formação de professores de língua inglesa para atuar como mediadores de contextos telecolaborativos como o do programa aqui apresentado.

\section{O Programa BRaVE}

O Programa BRaVE (Brazilian Virtual Exchange) foi criado pela FAUBAI (Associação Brasileira de Educação Internacional ${ }^{4}$ ) com o intuito de fomentar uma modalidade de aprendizagem colaborativa online que promova o contato intercultural e o intercâmbio de ideias ao conectar os alunos de graduação ou pós-graduação brasileiros com estudantes de diferentes instituições de ensino superior do mundo. A ideia partiu da percepção

3 Para mais informações, ver: https://bit.ly/2KF9v5l.

4 Disponível em: http://www.faubai.org.br 
de que a mobilidade virtual tem crescido nos últimos anos como uma estratégia de internacionalização em casa (CROWTHER et al., 2001), ou seja, ela apresenta-se como uma opção de baixo custo para promover a internacionalização das universidades e a criação de redes na formação de profissionais interconectados para a aprendizagem global.

A experiência da UNESP com telecolaboração já advém de um projeto de grande alcance criado em 2006, o Teletandem Brasil (http://www.teletandembrasil.org/), que coloca pares de falantes de diferentes línguas trabalhando de forma colaborativa por meio de recursos de comunicação síncrona ou assíncrona na Internet para aprenderem a língua um do outro (TELLES; VASSALLO, 2006; TELLES, 2009). Como o foco do Teletandem é a aprendizagem de línguas, ele foi estabelecido nos campi junto aos cursos de Letras, em Assis, São José do Rio Preto e Araraquara, com foco também em pesquisas na área de Estudos Linguísticos.

O Programa BRaVE não tem como principal foco a aprendizagem de línguas, mas o estabelecimento de contato intercultural e o intercâmbio de ideias ao conectar os alunos com estudantes de diferentes instituições de ensino superior do mundo. A proposta é que os professores da UNESP e seus parceiros universitários no exterior trabalhem de forma colaborativa para estabelecerem objetivos de aprendizagem comuns em disciplinas de graduação ou pós-graduação, por meio de tarefas que engajem os alunos a aprender conjuntamente por meio de tecnologias digitais. O contato estabelecido entre as turmas pode ser totalmente online, com interações síncronas ou assíncronas, ou em formatos híbridos, buscando-se criar um contexto que enfatize a aprendizagem por meio da experiência e construção conjunta de conhecimento.

Há várias instituições no exterior que já realizam esse tipo de parcerias. Algumas das mais conhecidas iniciativas para o estabelecimento de intercâmbios virtuais na atualidade são: Collaborative Online International Learning (COIL) ${ }^{5}$ da State University of New York (SUNY), EUA; Global Learning Experience (GLE) ${ }^{6}$, da De Paul University, EUA; Global Classroom7, da Drexel University, EUA; Online International Learning (OIL) ${ }^{8}$, da Coventry University, Reino Unido; Unicollaboration ${ }^{9}$, um projeto de diversas instituições de ensino superior na Europa.

\footnotetext{
5 http://coil.suny.edu

6 https://bit.ly/3bMlx82

7 http://drexel.edu/oip/academics/global-classroom/

8 https://bit.ly/2yPEBoj

9 https://uni-collaboration.eu/classes_list
} 
Apesar das diferentes nomeações, todas essas iniciativas têm em comum o objetivo de promover o contato intercultural por meio das tecnologias digitais, fazendo com que a aprendizagem ultrapasse a perspectiva local ao se inserir novos interlocutores em sala de aula. Desde 2018, professores de diferentes áreas implementaram ações de intercâmbio virtual no BRaVE-UNESP, como pode ser visto no quadro a seguir:

Quadro 1. Exemplos de intercâmbio virtual no BRaVE-UNESP em diferentes disciplinas/ áreas

\begin{tabular}{|c|c|c|c|c|}
\hline \multicolumn{5}{|c|}{ Intercâmbios já realizados no BraVE } \\
\hline Professor UNESP & disciplina/área & grad ou pós & quando & parceiro estrangeiro \\
\hline S./Botucatu & Medicina & graduação & $\begin{array}{c}1^{\circ} \text { semestre } \\
2018\end{array}$ & Universidade de Keele \\
\hline A./Araraquara & Língua inglesa & graduação & $\begin{array}{c}1^{\circ} \text { semestre } \\
2018\end{array}$ & \begin{tabular}{|c} 
University of Valladolid \\
National Taichung University of Education - \\
Taiwan \\
University of Bordeaux
\end{tabular} \\
\hline V./ Bauru & $\begin{array}{c}\text { Práticas pedagógicas } \\
\text { inclusivas }\end{array}$ & $\begin{array}{l}\text { pós, mas aceita } \\
\text { alunos de } \\
\text { graduação }\end{array}$ & $\begin{array}{c}2^{\circ} \text { semestre } \\
2018\end{array}$ & SUNY \\
\hline O./Säo Vicente & $\begin{array}{l}\text { "Urban plant ecology and } \\
\text { botany: a contrast of } \\
\text { countrics and scasons" }\end{array}$ & $\begin{array}{l}\text { graduaçào } \\
\text { (optativa) }\end{array}$ & $\begin{array}{c}2^{\circ} \text { semestre } \\
2018\end{array}$ & De Paul University \\
\hline P./ IBILCE & $\begin{array}{c}\text { Tradução e Português como } \\
\text { língua estrangeira }\end{array}$ & graduação & $\begin{array}{c}2^{\circ} \text { semestre } \\
2018\end{array}$ & University College London \\
\hline D./Guaratinguctá & Robótica & $\begin{array}{l}\text { graduação } \\
\text { (optativa) }\end{array}$ & $\begin{array}{c}2^{\circ} \text { semestre } \\
2018\end{array}$ & De Paul University \\
\hline L./Sorocaba & Chemistry and Biochemistry & pós & $\begin{array}{c}1^{\circ} \text { semestre } \\
2019\end{array}$ & De Paul University \\
\hline G./IBILCE & Literatura & graduação & $\begin{array}{c}1^{\circ} \text { semestre } \\
2019\end{array}$ & De Paul University \\
\hline R./Tupã & Environmental studies & graduação & $\begin{array}{c}2^{\circ} \text { semestre } \\
2019\end{array}$ & Tompkins Cortland Community College \\
\hline
\end{tabular}

Fonte: Elaboração própria

Como se pode observar, as ações de intercâmbio virtual foram realizadas em disciplinas das áreas de Ciências Humanas, Biológicas e Exatas, tendo como parceiros estrangeiros professores de universidades estadunidenses (SUNY, De Paul University, Tompkins Cortland), inglesas (Keele University e University College London), além de uma espanhola (Universidad de Valladolid), uma francesa (Université de Bordeaux) e uma taiwanesa (National Taichung University of Education). A língua de comunicação usada nestes intercâmbios foi o inglês como língua franca (SEIDLHOFER, 2011). Entretanto, é importante salientar que o Programa BRaVE, por seu caráter multilíngue, sugere que o idioma de interação com o parceiro do exterior e entre os discentes seja de escolha dos docentes envolvidos.

Há diversas maneiras de incluir o intercâmbio virtual nos programas das disciplinas, que podem ser obrigatórias ou optativas. Os professores interessados em participar do BRaVE podem trabalhar com parceiros que já conheçam ou buscar novas parcerias com a ajuda da coordenação do Programa. As atividades a serem realizadas devem 
ser planejadas conjuntamente pelos professores parceiros com vistas ao uso de ferramentas tecnológicas de comunicação e ao emprego de metodologias ativas de ensino-aprendizagem.

Apresenta-se, a seguir, as atividades realizadas por quatro professores que desenvolveram intercâmbios virtuais em diferentes áreas, constantes no Quadro 1, a saber O./São Vicente, S./Botucatu, V./Bauru e D./Guaratinguetá, uma vez que contaram com formas distintas de organização e interação entre os alunos.

\subsection{A disciplina "Urban plant ecology and botany: a contrast of countries and seasons"}

Esta disciplina foi oferecida como disciplina optativa no campus da UNESP de São Vicente e na De Paul University, em Chicago, nos EUA. As atividades de intercâmbio virtual na disciplina duraram 6 semanas entre 17 de setembro e 30 de outubro de 2018. Os alunos foram separados em 12 grupos que correspondiam a um mês do ano. Estes também foram posteriormente associados em conjuntos maiores que corresponderiam às quatro estações. Cada equipe de alunos brasileiros escolheu uma imagem de Chicago (ou dos EUA) e produziu um texto em inglês, que ilustrasse o mês que estavam responsáveis, dentro dos temas Ecologia Vegetal Urbana e Botânica Clássica. Os alunos brasileiros colheram imagens e informações através dos seus pares da De Paul University. O mesmo aconteceu com as doze equipes da De Paul, que escolheram uma imagem que ilustrasse o mês do ano de São Vicente (ou Brasil), seguido de um pequeno texto em português. Ao final, os materiais foram trocados para os alunos brasileiros avaliarem o produto dos estadunidenses e vice-versa. No Brasil, houve também uma avaliação em forma de seminário, na qual cada grande grupo, correspondente a uma estação do ano, fez uma apresentação oral de suas atividades. O produto dessa atividade foi um calendário bilíngue.

A imagem a seguir ilustra o mês de abril do calendário produzido em conjunto pelos alunos. 

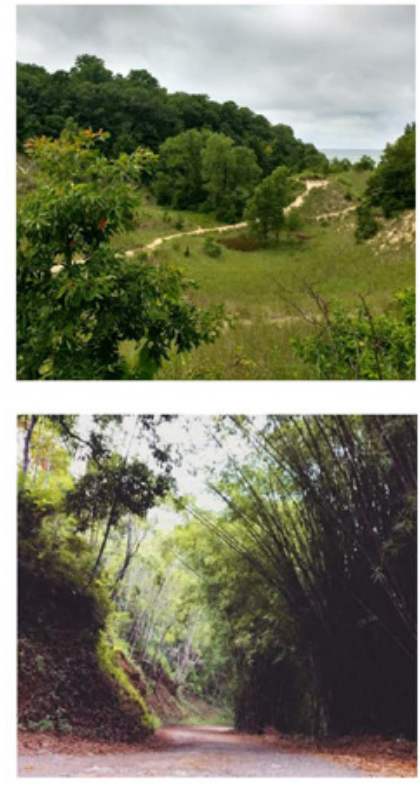

\section{EUA I SA}

Abril é um mês frio e sombrio no melo da primavera o céu é frequentemente coberto de nuvens e a chuva é comum. Com uma média de cerca de $15 \cdot \mathrm{C}$. o aumento das temperaturas permite que a folhagem se recupere dos meses de inverno. No dia 22 de abril celebramos o Dia da Terra, um dia que inspira a proteçăo ambiental.

April is a cool and gloomy month in the middle of spring The sky is often cloudy and raine are common. With an The cky is ofton cloudy and rains are common. With an average of around isc, the increasing temperatures allow the follage to recover from the winter months. On the 22nd of April. we celebrate Earth Day, a day to inspire Environmental awareness and protection.

\section{BRASIL / BRAZIL}

Abril no Brasil ć caracterizado por chuvas e altemância de dias mais quentes e mais amenos, ainda com um resquício de verăo No dia 21 de Abril celebramos o dia de Tiradentes, o aniversário de sua morte (21 de Abril) representa a luta pela independência do Brasil.

April in Brazil is characterized by rains and alternation of and ander days, still as a remnant of summer. On Ap 21st. we celebrate Tiradentes Day, the anniversary of his death, that represents the fight for the independence of Brazil

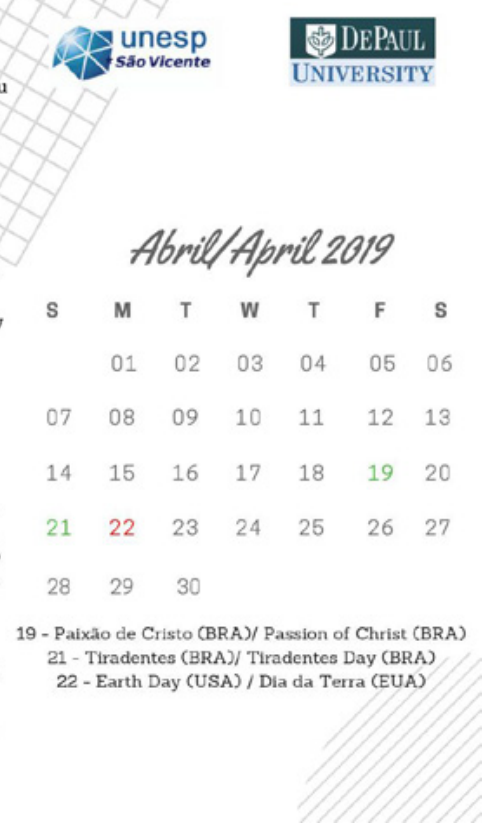

Figura 1. Calendário produzido em conjunto pelos alunos brasileiros e estadunidenses

Fonte: https://bit.ly/2S4CLXV

\subsection{Intercâmbio virtual no curso de Medicina}

Outro exemplo de intercâmbio virtual no BRaVE-UNESP foi realizado no curso de Medicina no campus de Botucatu, em uma disciplina que utilizou a metodologia PBL (Problem-based learning). Previamente ao início das atividades de intercâmbio virtual, os professores da UNESP e da Keele University escolheram um caso clínico e criaram perguntas norteadoras para trabalho em grupos pequenos formados por alunos de ambas as universidades. Foi também realizada uma aula com a definição de conceitos de doença viral, vírus, vacina. Foi realizada uma primeira sessão síncrona de videoconferência entre as turmas para as apresentações dos participantes: cada aluno se apresentava e falava um pouco sobre seus interesses e suas expectativas em relação ao curso. Em seguida, nessa mesma sessão, foi feita a apresentação do caso clínico pelos professores e aberta a discussão para os alunos, que sugeriram diferentes diagnósticos relativos aos seus entornos epidemiológicos. A partir disso, os alunos receberam a orientação de interagir com seus respectivos grupos nas semanas seguintes por meio de algum aplicativo digital para responder a uma pergunta norteadora. Segundo a professora responsável, o aplicativo escolhido foi o WhatsApp, que permitiu que compartilhassem suas perspectivas nas discussões a respeito da atividade como também abriu oportunidade para outros assuntos, como "troca de gifs, piadas etc.". Ela relatou ainda que um dos três grupos teve pouca interação além das necessárias para responder à pergunta, enquanto os outros dois tiveram interações maiores. 


\subsection{Disciplina "Práticas Pedagógicas Inclusivas"}

Um outro exemplo de trabalho colaborativo se deu na área da educação, com foco na inclusão, na disciplina "Práticas Pedagógicas Inclusivas" do campus de Bauru. As atividades foram incluídas em uma disciplina regular de graduação no Brasil e uma disciplina online de graduação na SUNY, EUA. Das quinze semanas de duração das disciplinas, quatro tiveram atividades de intercâmbio virtual como se pode ver no quadro a seguir.

Quadro 2. Programa conjunto da disciplina Práticas Pedagógicas Inclusivas/Inclusive Pedagogical Practices

1. Week 1 (Mar. 11-Mar. 25): Introduction (Content: Collaboration \& History) Introduction video due via the closed Facebook group: 11:59pm Mar. 25 (US ET)

2. Week 2 (Mar. 25-Apr. 1): Video Analysis \& Reflection (Content: Visual Impairment \& Hearing Impairment) - Video Analysis due via the closed facebook site: 11:59pm Apr. 1 (US ET)

3. Week 3 (Apr. 1-Apr. 8): Article Analysis \& Reflection (Content: Physical Disability) Article Analysis due via the closed facebook site: 11:59pm Apr. 8 (US ET)

4. Week 4 (Apr. 8-Apr. 29): Team Presentation Preparation (Content: Intellectual Disability) - Team Presentation due via the closed facebook site: 11:59pm Apr. 29 (US ET)

Fonte: Arquivos da professora responsável pela disciplina

Foi criado um grupo fechado de Facebook no qual todos os alunos foram inseridos, mas de acordo com a professora brasileira foi permitido também que os alunos usassem outros meios de comunicação para realizarem as atividades em conjunto. Primeiramente, os alunos se apresentaram por meio de vídeos postados no grupo fechado para que todos se conhecessem. Nas semanas dois, três e quatro, foram montadas equipes que se dividiram a partir do foco em diferentes tipos de deficiências (auditiva, visual, física e intelectual) e realizaram análises de vídeos e leitura de artigos relacionados aos temas estudados. Os resultados das equipes foram compartilhados no grupo fechado de Facebook para discussão entre todos os alunos. Ao final, os brasileiros realizaram também apresentações presenciais na aula para refletir sobre os conteúdos estudados e a experiência de trabalhar conjuntamente com os alunos estrangeiros. 


\subsection{Introdução à Robótica}

O curso Introdução à Robótica, do campus de Guaratinguetá, contou com atividades síncronas com os alunos da De Paul University, EUA. A comunicação entre os alunos foi conduzida pelos professores de cada instituição por meio de videoconferência entre ambas as turmas. O aplicativo usado foi o Zoom (https://zoom.us/), que permite diferentes configurações de interação entre os participantes. Em alguns momentos, as conversas foram realizadas em conjunto, por meio da projeção da imagem de ambos os grupos de alunos em um telão e uso de microfone para captar as vozes. Em outros momentos, a interação foi realizada colocando os alunos em seus respectivos grupos em salas de bate-papo separadas. Além das aulas síncronas, os alunos também poderiam se comunicar com seus pares por meio de outros aplicativos para desenvolver as atividades propostas antes ou depois das aulas. A disciplina consistiu na montagem de robôs e competições entre os grupos.

Houve ainda disciplinas voltadas à temática da tradução e português como língua estrangeira, química e bioquímica, literatura e ficção, língua inglesa e estudos do meioambiente. Não detalharemos todas elas, por questões de espaço e também porque as estratégias e recursos pedagógicos usados foram muito semelhantes às das outras disciplinas já descritas, com atividades a ser desenvolvidas em grupos formados por alunos de ambos os países por meio de ferramentais digitais. A pesquisa aqui relatada visou explicitar as estratégias usadas pelos professores para a implementação das atividades no que tange às dificuldades encontradas e tipos de atividades propostas para lidar com a heterogeneidade de competência linguístico-comunicativa dos alunos brasileiros. Buscamos também refletir sobre o papel do professor de língua inglesa como um possível mediador desses novos contextos de aprendizagem colaborativa.

\section{Metodologia da pesquisa}

Optamos por uma pesquisa de cunho qualitativo (DORNYEI, 2007), na qual pudéssemos explorar as perspectivas dos professores sobre as dificuldades para a comunicação entre os alunos e as estratégias criadas para lidar com elas durante o período das atividades de intercâmbio virtual. Os dados utilizados para o desenvolvimento da discussão proposta neste artigo foram coletados por meio de a) um questionário aplicado aos professores que realizaram atividades no BRaVE, assim como b) a transcrição e análise das falas de cinco deles em uma reunião online aberta a todos os docentes da universidade, que teve o intuito de apresentar o programa à comunidade por meio de exemplos de atividades já implementadas.

A reunião online ocorreu no dia 27/05/2019 por meio do aplicativo de videoconferência Zoom, com duração total de duas horas, sendo que a coordenadora do BRaVE 
primeiramente fez uma breve apresentação do programa e, posteriormente, cada docente falou por cerca de 15 minutos, com espaço ao final para perguntas. A reunião foi gravada em áudio e vídeo e os trechos em que os professores falaram sobre suas atividades foram transcritos para posterior análise. Os professores que apresentaram suas atividades no BRaVE foram cinco dentre aqueles constantes no Quadro 1, a saber: S./Botucatu, V./Bauru, O./São Vicente, D./Guaratinguetá, G./IBILCE. Todos os participantes deram permissão para o uso dos dados e inclusive alguns permitiram o uso de seus nomes reais, mas optamos por manter uma letra inicial e a cidade em que fica o campus ao qual pertencem.

O questionário com perguntas de respostas abertas foi enviado posteriormente por e-mail aos professores constantes do Quadro 1, sendo que sete deles responderam os mesmos da reunião online e também L./Sorocaba e R./Tupã. As questões foram: 1 - Qual foi a estratégia adotada para uso do inglês nas atividades colaborativas de virtual exchange? Essas estratégias foram indicadas por você ou criadas pelos próprios alunos? 2 - Quais foram as maiores dificuldades enfrentadas em relação à língua inglesa?

Foi feita uma análise de conteúdo na qual buscamos verificar as recorrências temáticas nas respostas dos professores tanto em suas falas na reunião quanto nas respostas aos questionários. Por meio da análise foram levantadas as seguintes categorias: a) inglês como pré-requisito, b) dificuldades com compreensão e produção oral e terminologia da área em língua inglesa, c) estratégias ligadas ao planejamento das atividades e à divisão dos grupos.

\section{Análise e discussão dos dados}

Discutiremos separadamente as categorias encontradas por meio da análise de conteúdo, mas é importante ressaltar que elas se conectam, uma vez que as dificuldades estão imbricadas com as estratégias encontradas pelos professores para lidar com a comunicação dos alunos em língua inglesa.

\subsection{Inglês como pré-requisito}

Uma das temáticas que permeou a fala dos professores foi a necessidade de incorporar a língua inglesa no programa da disciplina como pré-requisito. Alguns deles já tinham esse elemento presente por se tratar de um curso ligado ao ensino e aprendizagem de línguas estrangeiras, como é o caso da prof. G./IBILCE: 
(01) As disciplinas do projeto que realizei com o J. S. são originalmente oferecidas em inglês. As estratégias utilizadas foram discussões online a respeito dos romances escolhidos para análise nos encontros no horário das aulas. [...] O John afirmou que meus alunos tiveram de trabalhar mais, pois fizeram tudo em inglês, mas que a interação com os brasileiros tornou os alunos dele mais cosmopolitas. Meus alunos sentiram a diferença entre o inglês utilizado academicamente e o inglês informal do WhatsApp. (Prof. G., questionário)

Dentre os professores participantes desta pesquisa, a professora G. era a única que se encontrava em um curso voltado à formação de professores de línguas, e, portanto, com disciplinas geralmente já oferecidas em língua estrangeira. Observamos em seu relato que o uso do inglês, mesmo sendo considerado já parte integrante da disciplina, gera a ideia de que os alunos brasileiros "trabalharam mais" do que os estrangeiros, que realizaram as atividades em sua língua materna. Ainda assim, para os alunos brasileiros nessa disciplina, por se tratarem de professores em formação, houve a oportunidade de entrar em contato com diferentes registros da língua inglesa em conversas espontâneas com seus parceiros de grupo nas atividades realizadas em conjunto.

O professor D./Guaratinguetá, por outro lado, que dava aulas em um curso de engenharia, afırmou que sua primeira preocupação foi pensar sobre a viabilidade de se oferecer uma disciplina em outra língua dentro da instituição:

(02) [...] como eu vou fazer isso de forma oficial dentro da Unesp? Então eu fui, consultei conselho de curso, DTA, e se concluiu que nada impede de eu oferecer uma matéria em inglês, já que foi optado por estar oferecendo a matéria toda em inglês. Aqui está a ementa [...] a matéria chama Introduction to Robotics, mas ela tem os tópicos, tudo em inglês e a tradução em português para todos os itens que constam nela. E quando ela está lá oferecida para os alunos eles sabem que a língua vai ser o inglês, porque isso poderia causar um problema burocrático, não saber isso de antemão. (Prof. D., reunião online)

Como se pode ver em seu relato, tanto a ementa quanto o programa da disciplina foram traduzidos para o inglês e os alunos sabiam de antemão que essa língua seria usada para interação nas aulas. De fato, essa última foi uma preocupação da maior parte dos professores: que os alunos estivessem cientes da necessidade de ter conhecimento de língua inglesa para se inscrever na disciplina, como se pode ver exemplificado nos excertos a seguir. 
(03) O curso foi oferecido como sendo feito em inglês, desta forma, domínio da língua inglesa foi um critério de seleção dos alunos. (Prof. S., questionário)

(04) Inicialmente eu coloquei como pré-requisito para matrícula na disciplina optativa conhecimento em inglês (embora, eu não pedi nenhum certificado, ou fiz qualquer teste de proficiência), o aluno apenas declarava que tinha inglês intermediário ou fluente. Durante o curso, os alunos resolveram o problema do inglês se comunicando principalmente através de mensagens de texto e/ou por e-mail. (Prof. O., questionário)

Nota-se que muitas vezes a razão pela qual a disciplina foi oferecida como optativa foi justamente para inserir o pré-requisito linguístico com o intuito de garantir que os alunos fizessem uma escolha deliberada ao se matricular nela. Essa preocupação dos professores provavelmente se devia ao fato de que o BRaVE era um programa novo na instituição, e, portanto, possivelmente desconhecido aos alunos. Ademais, por ser uma primeira experiência da maior parte dos professores com esse tipo de atividade, isso também visou facilitar o envolvimento dos alunos nas atividades propostas.

\subsection{Dificuldades com compreensão oral e produção oral e terminologia da área}

Uma das dificuldades mencionadas pelos professores em relação à comunicação dos alunos em língua inglesa foi relacionada à compreensão oral, principalmente nas atividades que envolveram encontros síncronos por meio de videoconferência.

(05) Espero que eu consiga incluir mais docentes para que a gente consiga oferecer isso para todos os alunos ou uma grande parte, porque hoje nós trabalhamos com cinco ou sete alunos, por turma, então acaba sendo bastante eclético e eletivo para um grupo suprassumo é... acho que embora você não precise ser talvez fluente em inglês, você tem que ter um bom inglês para fazer, não adianta. Você fazer discussão... ao vivo no áudio onde a transferência nem sempre é ótima e é... atrapalha bastante. (Prof. S., reunião online)

(06) Apesar de todos os alunos terem se declarado com nível médio ou avançado em Inglês, a comunicação oral não fluiu como eu gostaria. O maior problema aconteceu nos encontros síncronos (os alunos se comunicaram pouquíssimo), devido a dois fatores (timidez e falta de prática em conversação em inglês). Assim, para a próxima edição do nosso $V E$, vamos tentar criar novas estratégias para estimular os alunos a se comunicarem mais, e também vamos reduzir os encontros síncronos (até porque a conexão de internet não ajuda muito, em nosso campus é um tanto quanto instável). (Prof. O., questionário) 
(07) A maior dificuldade sempre é falar, os estudantes brasileiros (não sei porque e de onde vem isso) tem medo de falar em inglês. O restante, ler e escrever aparentemente não é um grande problema. (Prof. L./questionário)

Nota-se pela fala da professora S. que muitas vezes o fato de a disciplina ser ministrada em inglês e contar com atividades de comunicação oral síncrona faz com que os grupos se tornem pequenos, pois poucos alunos se inscrevem. Já o professor 0 . relata que o nível declarado de conhecimento linguístico pelos alunos não foi condizente com suas performances nas interações orais síncronas. Os fatores elencados por ele, como a timidez e a falta de prática em conversação, assim como o medo de falar inglês, mencionado pelo prof. L., nos parecem ser problemas estruturais na aprendizagem de línguas no Brasil, uma vez que uma gama de estudos aponta para as dificuldades de comunicação oral em língua inglesa dos alunos brasileiros (FARIAS et al., 2008; GIL, 2009; HASHIGUTI, 2017), assim como de professores (TEIXEIRA DA SILVA, 2000, 2008; CONSOLO; TEIXEIRA DA SILVA, 2011). A fala do prof. O. já aponta para uma reflexão sobre estratégias para lidar com as dificuldades de um ponto de vista prático, mas que não envolvem necessariamente elementos diretamente relacionados às questões linguísticocomunicativas envolvidas, como discutiremos posteriormente.

As dificuldades com a compreensão oral também estiveram por vezes ligadas ao desconhecimento dos alunos de terminologia específica da área, como se pode ver no excerto a seguir.

(08) Acho que as maiores dificuldades foram compreensão com áudio algumas vezes borderline, sendo necessário repetir algumas colocações, e algumas situações com expressões de inglês médico que foram prontamente explicadas pelos parceiros. Demais, não tivemos dificuldades de comunicação, mesmo nas conversas entre os alunos (pelo WhatsApp) não houve algum relato de dificuldade pelos alunos, funcionou super bem. (prof. S., reunião online)

Como se pode notar, questões sobre dúvidas a respeito de determinados termos específicos da área em língua inglesa foram resolvidas por meio de explicações dadas pelos parceiros estrangeiros durante a interação. Concordamos com Paiva (2013) que a interação está no cerne da aprendizagem de línguas, uma vez que a razão pela qual se aprende línguas é para construir relações sociais. Entretanto, a autora adverte que, além de funcionar como importante apoio para a aprendizagem, a interação também pode ocasionar situações embaraçosas, e por isso requer especial atenção por parte dos professores. Nesse sentido, entendemos que a Linguística Aplicada pode contribuir para a compreensão do conceito de interação em língua estrangeira no planejamento de atividades de intercâmbio virtual. Discutiremos a seguir as estratégias usadas pelos 
professores e então discorremos sobre como vemos o papel dos linguistas aplicados no que tange à potencialização dos recursos linguísticos em tais contextos.

\subsection{Estratégias ligadas ao planejamento das atividades e à divisão dos grupos}

Nota-se que algumas das estratégias usadas pelos professores para lidar com a comunicação em língua inglesa já foram incorporadas desde o planejamento das atividades em conjunto. Como relata o prof. O., no excerto a seguir, a busca por inserir outras semioses, que pudessem auxiliar a criação e negociação de significados entre os participantes, foi uma escolha respaldada na ideia de facilitação da comunicação:

(09) [...] a ideia que eu tive desde o começo foi fazer um calendário bilíngue, onde os alunos pudessem compartilhar ideias e fotos, e informações biológicas. Como a língua, eu sabia que ia ser uma forma de barreira, eu achei que eles pudessem trabalhar com imagens, seria mais fácil de tentar ilustrar esse conhecimento e também quebrar o gelo. (Prof. O., reunião online)

Outra estratégia importante, principalmente para aqueles que optaram pela comunicação síncrona em sala de aula, foi conduzir a primeira interação dos alunos, facilitando a comunicação e colocando-os em pequenos grupos em salas separadas no aplicativo de videoconferência, com tarefas específicas a serem realizadas.

(10) Essa aula síncrona, essa primeira aula, é um ice-breaker, os alunos vão, se apresentam e a gente começa já fazendo uma atividade, a gente coloca grupos normalmente de dois alunos, ou três, em cada lado, aqui no próprio Zoom você consegue separar os alunos em grupos. Então, você tem a vídeo conferência principal e você consegue fazer como se fossem salas reservadas, então a gente coloca esses alunos em salas reservadas e eles vão discutir nesse caso lá a gente coloca um problema inicial, uma descrição, coloca características, uma situação de um robô para eles definirem quais características são importantes e eles têm que apresentar isso até o final da aula, e eles entregam isso. (Prof. D., reunião online)

A forma de dividir os grupos também pareceu ser uma estratégia intencionalmente usada pelos professores, como podemos ver nos excertos a seguir: 
(11) Uma estratégia que usamos foi trabalhar com grupos de estudantes. Em um primeiro momento grupos do Brasil e do USA para que eles se conhecessem e também não tivessem "vergonha" de falar e trabalhar em inglês entre eles e depois em um segundo momento grupos mistos. Essa estratégia foi indicada pelos docentes. (Prof. L., questionário)

(12) Então eu ministrei uma disciplina de quatro créditos, quinze semanas e na minha disciplina tinham alunos de biologia, é uma disciplina da graduação [... [ eu ofereci junto com a pós graduação e... então eu tinha licenciatura em biologia e alunos da psicologia da pós-graduação e da docência para a educação básica, que é o mestrado profissional, e de certo modo o inglês de todos é... de alguns é intermediário, alguns não tinham noção nenhuma, mas a gente cuidou que em cada grupo pelo menos uma pessoa a gente sabia que o inglês, pelo menos o básico, tinha. (Prof. V., reunião online)

(13) A estratégia foi identificar os alunos com melhor domínio de inglês e colocá-los para liderar diferentes grupos, dividindo os demais alunos nesses grupos. Além disso, dar confiança aos alunos no sentido de que não percam a motivação por causa da barreira linguística, estimulando a realizar a comunicação de forma escrita caso a oral esteja difícil. Foi indicada por mim. (Prof. D., questionário)

O Prof. L. afirma que primeiramente os brasileiros foram encorajados a conversar em inglês entre eles para criar um ambiente mais confortável aos alunos antes de interagir com os colegas estrangeiros. Já os professores $\mathrm{V}$. e O. buscaram identificar alunos com mais facilidade ou maior domínio da língua estrangeira para alocá-los nos diferentes grupos, de forma que atuariam como facilitadores para os colegas. Nesse sentido, vê-se que fizeram uso de apoio de par mais competente para auxiliar os colegas, provavelmente baseando-se no conceito de Zona de Desenvolvimento Proximal, de Vygotsky, aplicado ao universo da aprendizagem colaborativa. Paiva (2010) problematiza a utilização desse conceito e sua transposição no âmbito da aquisição de línguas para que não se romantize a atuação do par mais competente ou se minimize o papel de outros artefatos culturais que também podem ser mediadores na aprendizagem autônoma. Entendemos como a autora que isso "não anula a importância do papel do outro na aprendizagem, mas nos faz ver o contexto social não apenas como ambiente de cooperação, mas, também, como arena de conflitos e de frustrações" (p. 205).

Assim, ainda que o foco não esteja na interação em língua estrangeira em si, mas na possibilidade de criarem formas de se trabalhar em conjunto na construção de conhecimento ao realizarem uma atividade colaborativa à distância, há que se pensar em formas de fornecimento de andaimes que possam auxiliar a interação, potencializando as habilidades trazidas pelos alunos. 
Um dos professores relata que deixou que os próprios alunos escolhessem os líderes dos grupos, a partir de suas percepções sobre a competência linguístico-comunicativa de cada um.

(14) Foi sugestão minha permitir o uso do google translator e eleger líderes e co-líderes de grupos com maior fluência. A eleição era com os alunos, tornando o processo participativo. (Prof. R., questionário)

Vê-se também que ele sugeriu o uso do Google tradutor para auxiliar a comunicação entre os alunos. Essa estratégia parece ter sido direcionada para os alunos que usavam também ferramentas de comunicação síncrona escrita, como WhatsApp, Facebook, ou assíncrona, como e-mail, para realizar as atividades propostas.

O excerto a seguir conjuga a questão do uso do tradutor e da importância de um par mais competente para atuar como facilitador da interação entre os grupos:

(15) [...] aí ela fez o convite e eu estava preparada para fazer de novo no segundo semestre, mas quando ela ofereceu para fazer já no primeiro, eu não tinha essa possibilidade de fazer junto, graduação e pós-graduação, então eu fiz só com a graduação e quer queira quer não, eu fiz com a turma só da pedagogia e o que aconteceu? Eu não vou dizer que foi geral porque eu fui segunda-feira passada na turma e não foi unânime, eu... se pudesse... se falar assim aí mas você avalia que não foi positivo com nenhum grupo? Não, teve grupo que foi positivo, que teve interação, mas para metade da turma ou até um pouquinho mais a dificuldade total do inglês e não ter esse alguém no grupo do Brasil, dificultou o trabalho, então o que que eles relatavam para mim? Que na hora da interação, como daqui não tinha ninguém, eles tinham dificuldade em entender o inglês [...] que eles colocavam no Google tradutor e não havia alguém fluente ou básico em inglês e português para fazer essa articulação... (Prof. V., reunião online)

Os dados apontam que ferramentas de tradução online podem facilitar a versão da língua para compreensão e possivelmente a produção (principalmente na comunicação assíncrona), mas isso talvez não dê conta da necessidade de articulação entre os grupos para a realização do trabalho colaborativo, como se pode ver no relato da professora, uma vez que há uma gama de fatores envolvidos nesse tipo de atividade colaborativa. O'Dowd e Ritter (2006) identificaram quatro níveis de fatores que podem contribuir para o insucesso na comunicação em projetos telecolaborativos: individual, da sala de aula, socioinstitucional e interacional. O fator individual está relacionado ao nível de competência comunicativa intercultural do aprendiz, assim como sua motivação e expectativas em relação à aprendizagem da língua estrangeira e estereótipos que os participantes têm a respeito de seus parceiros de intercâmbio virtual. No nível da sala de 
aula, os fatores envolvem a relação entre os professores parceiros, as tarefas propostas, a formação dos grupos e a dinâmica local de interação entre os aprendizes. O nível socioinstitucional inclui as tecnologias usadas, a organização dos diferentes cursos no que tange à conciliação de diferentes calendários escolares, fusos horários, carga horária e métodos de avaliação. E, por fim, no nível interacional, os autores apontam para as diferenças culturais nos estilos de comunicação e comportamentos, principalmente relacionadas à comunicação não-verbal, à franqueza para expressar-se, ao uso de humor e ironia.

De forma geral, os dados mostram que uma das chaves para lidar com a comunicação em língua inglesa está justamente na forma como o professor planeja e organiza as atividades, seja pela inclusão de comunicação multimodal, uso de ferramentas de tradução, escolha de um líder por grupo, facilitação da interação face a face pelo professor e pelo contato com os colegas de classe primeiramente em língua estrangeira. Algumas dessas estratégias parecem ter sido pensadas desde o planejamento das atividades, enquanto outras provavelmente foram incorporadas no decorrer do processo de colaboração, movidas pelas necessidades e dificuldades apresentadas pelos alunos.

Discutiremos, a seguir, as possíveis contribuições da Linguística Aplicada para os contextos de intercâmbio virtual que poderão incrementar tais estratégias a partir de uma perspectiva que leve em consideração as potencialidades linguísticas dos estudantes.

\section{0 papel do linguista aplicado em contextos de intercâmbio virtual}

Oportunidades de prática na língua estrangeira são importantes para o desenvolvimento da competência linguístico-comunicativa dos aprendizes, e, por isso, acreditamos que há a necessidade de se criar estratégias específicas ao incluir esse tipo de atividade no intercâmbio virtual, principalmente por professores cuja especialidade não é o ensino de línguas. Para isso, seria importante uma parceria com um professor de língua estrangeira, que poderia auxiliar, com aportes teóricos da Linguística Aplicada (LA), a reflexão sobre estratégias para facilitar a comunicação entre os alunos. A mediação linguística é geralmente desapercebida pelas pessoas em geral, entretanto a LA se constitui em forma de modelos e paradigmas que permitem ao linguista aplicado "usufruir de uma compreensão abrangente e articulada do mundo de usos de linguagem em que precisamos viver" (ALMEIDA FILHO, 1991, p. 5).

Uma vez que cada contexto de intercâmbio virtual é único, pois depende de fatores como número de participantes, conteúdos e objetivos de ensino dos professores envolvidos, nível de proficiência na língua escolhida para comunicação, recursos digitais disponíveis, tempo e duração das atividades, entre outros, as estratégias para lidar principalmente com as questões linguísticas também deverão ser criadas de acordo com os elementos presentes, que muitas vezes se apresentam de forma imbricada. Por exemplo, o fuso 
horário pode interferir na escolha do modo de comunicação, síncrono ou assíncrono; as ferramentas digitais disponíveis deverão ser adequadas ao número de participantes; e, acima de tudo, ao colocar em contato falantes de diferentes línguas, as escolhas feitas devem ainda ser condizentes com a competência linguístico-comunicativa em língua estrangeira dos participantes.

Nesse sentido, com o auxílio de um profissional de LA, estratégias poderiam ser criadas, para aprofundar, facilitar, reter o conhecimento e uso das novas expressões antes, durante e depois do contato. Poder-se-ia, por exemplo, trazer ao conhecimento dos professores estudos que visam à compilação de glossários de colocações, assim como pesquisas sobre inglês para fins acadêmicos, que poderiam contribuir para a criação de estratégias de aprendizagem para lidar com terminologia específica da área. Ainda, o arcabouço teórico de EMI (English as a medium of instruction) e CLIL (Content and Language Integrated Learning), que tem ganhado destaque atualmente no processo de internacionalização das universidades, também poderia trazer contribuições para os professores que realizam o intercâmbio virtual, uma vez que ambas as propostas possuem características em comum no que tange ao uso do inglês no ensino-aprendizagem por/para falantes não-nativos. Embora EMI tenha sido mais referenciado no contexto universitário e CLIL seja uma abordagem predominante nas escolas primárias e secundárias, ambos podem auxiliar o planejamento de atividades baseadas em projetos ou problemas, com envolvimento ativo dos alunos, suporte à produção linguística e oportunidades para esclarecer terminologias.

No que tange ao uso de outras línguas ou da ampliação da perspectiva dos professores em relação à comunicação em língua estrangeira, conceitos como o de translanguaging e o de intercompreensão certamente abrirão novos espaços de entendimentos sobre os modos como a fluidez da interação em contextos não-formais pode ser incorporada à educação na atualidade. Translanguaging significa ver as diferentes línguas conhecidas pelo indivíduo como um contínuo relacionado à sua história de vida e identidade, considerando o uso criativo que ele faz da língua(gem) como parte de seu conhecimento linguístico (GARCÍA; WEI, 2014). A intercompreensão, baseando-se na proximidade ortográfica, morfológica, sintática, lexical e/ou fonética entre as línguas de uma mesma família, visa facilitar a comunicação entre indivíduos, que ao se expressarem em seus próprios idiomas buscam compreender-se mutuamente. Tais conceitos poderão auxiliar a reflexão sobre o uso de diferentes línguas que não somente o inglês nesse tipo de atividades de intercâmbio virtual, assim como a inclusão dos recursos linguísticos que os estudantes já trazem em seus repertórios, em uma perspectiva plurilinguística que pode gerar a abertura para novas práticas interacionais em sala de aula e nas atividades online.

Ainda, temáticas como crenças e ensino de línguas (BARCELOS; VIEIRA-ABRAHÃO, 2006), identidade e aprendizagem de línguas (LEFFA, 2012), a dimensão afetiva na aprendizagem de idiomas (ANDRADE, 2011), cultura e interculturalidade (TAVARES, 2006; 
LIMA, 2012), dentre tantas outras ${ }^{10}$ já bastante difundidas na área de ensino de línguas, que geralmente não fazem parte da base de conhecimentos de professores de outras áreas, poderiam auxiliar o planejamento e a implementação de intercâmbios virtuais em língua estrangeira, de modo que essas atividades possam ser incluídas em disciplinas da grade obrigatória, e não somente nas optativas, o que significaria também ampliar o escopo da internacionalização em casa para mais estudantes.

Assim, vemos um espaço para o profissional de línguas estrangeiras ao poder aliar seu conhecimento sobre aprendizagem de línguas ao contexto vivenciado pelos participantes de intercâmbios virtuais. Trata-se de uma atividade diferente do que geralmente se está acostumado a pensar para o professor de língua estrangeira, pois não envolve o ensino da língua em si, mas a criação de estratégias para facilitar a comunicação por meio da compreensão das possibilidades do contexto e dos participantes, dos objetivos de ensino dos professores envolvidos e das ferramentas digitais disponíveis, para a proposição de tarefas que possam ser realizadas pelos alunos de forma a aproveitar as potencialidades em favor da comunicação.

\section{Considerações finais}

Neste artigo, buscamos propor algumas reflexões para a área de políticas de internacionalização nas universidades imbricadas com questões de ensino e aprendizagem de línguas a partir de um estudo sobre as dificuldades dos alunos para lidar com o uso do inglês em atividades de intercâmbio virtual inseridas por professores de diferentes áreas em suas disciplinas de graduação e pós-graduação no Programa BRaVE-UNESP, assim como as estratégias de enfrentamento usadas por eles. As maiores dificuldades explicitadas se relacionaram à compreensão e produção oral em língua inglesa, percebidas especialmente em sessões síncronas de videoconferência. Dentre as estratégias usadas, algumas se relacionaram ao oferecimento de disciplinas optativas e à sinalização para os alunos sobre a necessidade do conhecimento de inglês como prérequisito para matricular-se. Em relação ao planejamento das atividades, as estratégias principalmente focaram a distribuição dos alunos em grupos fazendo uso da presença de pelo menos um par mais competente na língua estrangeira, assim como permissão para uso de tradutores online e flexibilidade em relação a formas de comunicação por meio de aplicativos diferentes daqueles usados pelos professores para reunir as duas turmas.

10 Esclareço que os autores e obras citados visam ilustrar as temáticas mencionadas, uma vez que muitos deles organizaram livros que trazem uma gama de artigos sobre esses temas no ensino e aprendizagem de línguas em contexto brasileiro. Não se pretendeu realizar aqui um levantamento exaustivo, mas exemplificar e mostrar caminhos que podem servir como leitura inicial para aqueles que desconhecem tais assuntos. 
Ainda que tais estratégias tenham se mostrado eficazes, segundo os professores, elas acabam restringindo as possibilidades de oferecimento de atividades de internacionalização como essas ou de se ampliar o número de participantes, por não incluírem aspectos de enfrentamento relacionados às questões linguístico-comunicativas envolvidas nesse tipo de interação. Vemos, assim, no contexto da mobilidade virtual possibilitada por projetos como o BRaVE a abertura para se pensar um novo papel para o professor de língua estrangeira, que pode atuar como um mediador da parceria formada entre os professores interessados em realizar intercâmbios virtuais, que nem sempre serão especialistas em ensino de línguas, mas que certamente terão de propor estratégias para lidar com a comunicação na língua escolhida. Nesse sentido, esses professores poderiam ser auxiliados por meio do conhecimento sobre aportes teóricos da Linguística Aplicada, que abordam discussões sobre temas como a identidade do aprendiz de língua estrangeira, emoções na aprendizagem de línguas, estratégias de comunicação, interculturalidade, EMI, translanguaging, intercompreensão, entre outros, que podem ser desconhecidos pelos professores de diferentes áreas, mas que certamente os ajudaria a criar estratégias específicas para seus contextos.

Acreditamos que a modalidade de intercâmbio virtual entre professores de áreas que não a de ensino de línguas traz à tona esse novo papel de mediador ao profissional de Letras, que auxiliará o desenho do curso e/ou das atividades colaborativas por meio de seus conhecimentos sobre aprendizagem de línguas e comunicação em língua estrangeira. Nesse sentido, estamos também diante de um desafio para a Linguística Aplicada no que tange à reflexão sobre os componentes desse novo papel de mediador exercido pelo profissional de línguas estrangeiras, assim como à elaboração de diretrizes para a formação inicial e continuada para preparar os professores para atuar nos novos contextos de mobilidade virtual.

\section{REFERÊNCIAS}

ALMEIDA FILHO, J. C. P. Maneiras de compreender lingüística aplicada. Revista do Programa de Pós-graduação em Letras, UFSM, n. 2, p. 4-10, 1991.

ANDRADE, M. R. M. (org.). Afetividade e emoções no ensino/aprendizagem de línguas: múltiplos. Coleção: Novas Perspectivas em Linguística Aplicada. v. 18. Campinas: Pontes, 2011.

BARCELOS, A. M. F.; VIEIRA-ABRAHÃO, M. H. Crenças e ensino de línguas: foco no professor, no aluno e na formação de professores. Campinas: Pontes, 2006.

BRASIL. A internacionalização na Universidade Brasileira: resultados do questionário aplicado pela Capes. Edição e composição: Diretoria de Relações Internacionais. Capes, Brasília, 2017. Disponível em: https://www.capes.gov.br/images/stories/download/ diversos/A-internacionalizacao-nas-IES-brasileiras.pdf. Acesso em: 16 ago. 2019. 
CONSOLO, D. A.; TEIXEIRA DA SILVA, V. L. Desenvolvimento da proficiência oral em inglês em alunos universitários: análise de tarefas e da qualidade das interações verbais. In: SILVA, K. A.; DANIEL, F. G.; KANEKO-MARQUES, S. M.; SALOMÃO, A. C. B. A formação de Professores de Línguas: novos olhares. Campinas: Pontes, 2011. p. 127-146.

COYLE, D. Theory and planning for effective classrooms: Supporting students in content and language integrated learning contexts. In: MASIH, J. (ed.). Learning Through a Foreign Language: Models, Methods and Outcomes. London, CILT Publications, 1999.

CROWTHER, P.; JORIS, M.; OTTEN, M.; NILSSON, B.; TEEKENS, H.; WÄCHTER, B. Internationalisation at Home: A Position Paper. Amsterdam: EAIE, 2001. Disponível em: https://www.internationalisering.nl/wp-content/uploads/2015/04/Internationalisationat-Home-A-Position-Paper.pdf. Acesso em: 20 jan. 2020.

DORNYEI, Z. Research Methods in Applied Linguistics. Oxford: Oxford University Press, 2007.

FARIAS, M.; ARMENDÁRIZ,A. M.; GIL, G.; GIMENEZ, T.; N.; CLAVIJO OLARTE,A.;ABRAHAMS, M. J. Sociocultural and political issues in English teacher education: policies and training in Argentina, Brazil, Chile and Colombia. In: GIL, G.; VIEIRA-ABRAHÃO, M. H. Educação de Professores de Línguas: os desafios do formador. Campinas: Pontes: 2008. p. 23-44.

GARCÍA, O.; WEI, L. Translanguaging: Language, Bilingualism and Education. New York: Palgrave Macmillan, 2014.

GIL, G. O ensino do inglês, do português e do espanhol como línguas estrangeiras no Brasil e na Argentina: uma comparação glotopolítica. Helb, Brasília, v. 3, n. 1, 2009 [não paginado]. Disponível em: https://bit.ly/2z9iucJ. Acesso em: 16 ago. 2019.

HASHIGUTI, S. T. Can we speak English? Reflections on the unspoken EFL in Brazil. Trabalhos em Linguística Aplicada, Campinas, v. 56, n. 1, p. 213-233, 2017. Disponível em: http://dx.doi.org/10.1590/010318135150200431. Acesso em: 16 ago. 2019.

KRAMSCH, C. Cultura no ensino de língua estrangeira/ 'Culture in Foreign Language Teaching'. Bakhtiniana, São Paulo, v. 12, n. 3, p. 134-152, set. /dez. 2017.

LEFFA, V. J. Identidade e aprendizagem de línguas. In: SILVA, K. A.; DANIEL, F. G.; KANEKO MARQUES, S. M.; SALOMÃO, A. C. B. (org.). A formação de professores de línguas: novos olhares. v. 2. São Paulo: Pontes, 2012. p. 51-81. 
LIMA, D. C. (ed.). Language and its Cultural Substrate: Perspectives for a Globalized World. Campinas: Pontes, 2012.

O'DOWD, R. (ed.). Online Intercultural Exchange: An Introduction for Foreign Language Teachers. Clevedon: Multilingual Matters, 2007.

O'DOWD, R. From telecollaboration to virtual exchange: state-of-the-art and the role of UNICollaboration in moving forward. Journal of Virtual Exchange, n. 1, p. 1-23, 2018.

O'DOWD, R.; RITTER, M. Understanding and working with 'failed communication' in telecollaborative exchanges. CALICO Journal, v. 23, n. 3, p. 623-642, 2006.

PAIVA, V. L. M. O. O outro na aprendizagem de línguas. In: HERMONT, A. B.; ESPÍRITO SANO, R. S.; CAVALCANTE, S. M. S. Linguagem e cognição: diferentes perspectivas, de cada lugar um outro olhar. Belo Horizonte: Editora PUCMINAS, 2010. p. 203-217.

PAIVA, V. L. M. O. Interação e aquisição de segunda língua: uma perspectiva ecológica. In: GERHARDT, A. F. L. M.; AMORIM, M. A.; CARVALHO, A. M. (org.). Linguística aplicada e ensino de língua e literatura. Campinas: Pontes Editores, 2013. p. 187-205.

SALOMÃO, A. C. B. Vizinhança global ou proximidade imposta? Impactos da comunicação intercultural mediada por computador sobre o papel da cultura no ensino de língua inglesa. D.E.L.T.A., São Paulo, v. 27, n. 2, p. 235-256, 2011.

SEIDLHOFER, B. Understanding English as a Lingua Franca. Oxford: Oxford University Press, 2011.

TAVARES, R. R. Língua, cultura e ensino. Maceió: EDUFAL, 2006.

TEIXEIRA DA SILVA, V. L. Fluência oral: imaginário, construto e realidade num curso de Letras/LE. 2000. Tese (Doutorado em Linguística Aplicada) - Instituto de Estudos da Linguagem, Universidade Estadual de Campinas, Campinas, 2000.

TEIXEIRA DA SILVA, V. L. Em busca da fluência oral: um curso de Letras sub-judice. In: SILVA, K. A.; ALVAREZ, M. L. O. Perspectivas de investigação em Linguística Aplicada. Campinas: Pontes, 2008. p. 373-400. 
TELLES, J. A. (org.). Teletandem: um contexto virtual, autônomo e colaborativo para a aprendizagem de línguas estrangeiras no século XXI. Campinas: Pontes Editores, 2009.

TELLES, J. A.; VASSALLO, M. L. Foreign language learning in-tandem: Teletandem as an alternative proposal in callt. The ESPecialist, v. 27, n. 2, p. 189-212, 2006. 